I had the pleasure of attending EDUCAUSE Annual Conference from October 14-17, 2019. This was my first time at EDUCAUSE, but I was impressed with the variety of programs, vendors, and options for learning about technology and higher education. After recently completing my coursework for a second master's in educational technology, I was curious to see what new technologies would be highlighted at EDUCAUSE. I found out about some new trends, such as the growth of esports in high schools and higher education. Esports are when players or teams compete through computers in video game competitions. ${ }^{1}$

There were over 20 programs and sessions about virtual reality at EDUCAUSE. Since there were so many programs about virtual reality at EDUCAUSE, I wanted to share a little of what I learned including how some higher education institutions are creating VR content, using pre-created content, and VR in libraries.

Since virtual reality is still new to many higher education institutions, I wasn't sure how many would be creating content, but I did attend a couple of sessions about how 360 -degree content is being created. Virtual reality content creation seems to happen most frequently in the medical field so students can practice different procedures that may not happen very frequently in their jobs, allowing them to experience a wider variety of procedures that they will eventually encounter in the workplace. Health sciences libraries are generally ahead of the curve in providing VR services to patrons. ${ }^{2}$ Additionally, STEM areas are finding more uses for VR, such as VR laboratories so expensive lab equipment does not need to be purchased, but students can still participate in VR lab experiences.

Creating VR content using tools such as Unity can be difficult and time-consuming. Some educators are using 360-degree cameras to create virtual settings that can be used by students but are easier to create. Tim Fuller and Rich Kappel spoke about how they used a 360-degree camera and Matterport scans to create 360-degree virtual environments for students to explore and engage with robotics technology. Tags can then be added to include pictures, videos, or link to websites with more information. This creates a shareable link that can be used to share with students. I was able to use my iPhone and the Google Street View app to create a 360-degree tour of my library. It is not high quality enough to view in virtual reality with an Oculus Go or other VR headset, but it is a great starting point for creating a 360-degree virtual tour of a library on a budget. This was free (since I already had an iPhone). There is a wide variety of freely available, 360-degree content that can be used by educators in the classroom and more is being created.

What does this mean for libraries? While quick virtual tours can be created with smartphones, higher quality VR experiences can also be created by librarians using a 360-degree video camera. These experiences could be used to teach students information literacy skills or search strategies in a VR environment. While this would be harder to do right now with the technologies available,

Breanne Kirsch (Breanne.Kirsch@briarcliff.edu) is University Librarian, Briar Cliff University. 
it could become easier down the road. Meanwhile, librarians can create 360 -degree virtual tours. Libraries can offer VR services, such as a VR lab or checking out standalone VR headsets, such as Oculus Go or Oculus Quest. Just like with the Makerspaces trend, libraries are well situated to support virtual reality in education.

Our library circulates an Oculus Go and when we were considering adding a virtual reality headset, there were some risks we considered prior to purchasing it. There are health risks for some people when using virtual reality headsets, such as motion sickness, dizziness, and, in some cases, epileptic seizures. It is important to explain this to students before they check out the device, so they know to immediately quit using the Oculus Go if they have an adverse reaction. Additionally, we keep cleaning wipes with the Oculus Go to help keep it sanitary when multiple people are using it. A tablet or smart phone needs to be associated with the Oculus Go in order to update apps or download new apps. Therefore, a passcode needs to be added so students can't purchase paid apps on the Oculus Go with the associated credit card. Privacy can also be a concern, especially when using the social apps, which is why I decided not to download the social apps on the Oculus Go at this time. Some of the scary apps, such as the Face Your Fear app can cause students to scream, so it is important that students realize how realistic the experiences are before using them. One final consideration when offering VR services is staffing. There needs to be someone trained in the library that can help teach students how to use the VR headset and experiences. I've trained each of our student workers in how to use the headset so they can show other students.

While these are some important considerations when deciding whether to offer VR services or not, I believe the benefits outweigh the risks. Virtual reality is expected to continue to grow, especially with wireless headsets, such as the Oculus Go and Oculus Quest available. It is important for libraries to be ready to offer support with virtual reality, just as we've offered support for prior technologies including tablets, laptops, computers, 3D printers, etc. Libraries can start small, by circulating an Oculus Go or creating a 360-degree library tour. Libraries with more resources could create a VR lab or provide support for creating VR content, such as 360 -degree video cameras or tools like Unity. It will be exciting to see how libraries can support VR in the future.

\section{FURTHER READINGS}

Van Arnhem, Jolanda-Pieta, Christine Elliott, and Marie Rose. Augmented and Virtual Reality in Libraries. Lanham: Rowman \& Littlefield, 2018.

Varnum, Kenneth J. Beyond Reality: Augmented, Virtual, and Mixed Reality in the Library. Chicago: ALA Editions, 2019.

\section{ENDNOTE}

${ }^{1}$ Matthew A. Pluss, Kyle J. M. Bennett, Andrew R. Novak, Derek Panchuk, Aaron J. Coutts and Job Fransen, "Esports: The Chess of the 21st Century," Frontiers in Psychology 10, no. 156, 2019, https://doi.org/10.3389/fpsyg.2019.00156.

${ }^{2}$ Susan Lessick and Michelle Kraft, "Facing Reality: The Growth of Virtual Reality and Health Sciences Libraries," Journal of the Medical Library Association 105, no. 4, 2017, https://doi.org/10.5195/jmla.2017.329. 